\title{
AUTORIA ESCANCARADA: O CORPO EM CENA
}

\author{
Irineu E. JONES CORRÊA \\ Fundação Biblioteca Nacional - Brasil
}

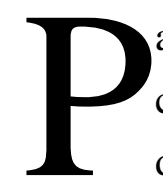

ara efeitos dessa apresentação, definirei literatura pornográfica como aquela que convoca, na composição do texto, sentimentos e comportamentos sexuais reconhecidos como degradantes, bárbaros ou animalescos, explicitados em linguagem de baixo calão e escatológica. Em sua constituição, ela é desprovida de metáforas suavizantes nas referências que faz a desejos, realizações e frustrações sexuais e na descrição dos corpos e de suas partes.

Essa relativa delimitação não significa negar a importância que é o estabelecimento das diferenças que distinguiriam e aproximariam discursos eróticos, obscenos, pornográficos e as possibilidades de efeitos que cada um deles teria para a literatura e para os estudos literários. Importantes teóricos se dedicam a este debate -Lynn Hunt, em língua inglesa, Georges Battaille, em língua francesa, e, no âmbito da análise do discurso, Dominique Maingueneau-.

As elaborações que faço começam pelo estabelecimento do contexto histórico e discursivo em que o corpus emerge -na direção proposta por Michael Foucault (1996)-.

O movimento que a estética do romantismo nomeia teve características muito especiais no Brasil. Foi assumido como discurso constituinte da nacionalidade que se instaurava junto com o novo império, que se separara de Portugal depois de mais de 300 anos de subordinação colonial. Em 1824, apenas passados dois anos da Independência política, que se deu em 1822, é publicado em Paris, um texto que propõe uma revisão do modo de fazer literatura no país, levando em conta como a «natureza» e os «grandes cenários» poderiam influenciar na imaginação dos escritores. $\mathrm{O}$ autor é Ferdinand Denis (1798-1890) -francês que vivera no país dos 16 até os 21 anos de idade-. Tendo ido ao Brasil com intuitos comerciais, de fazer fortuna, ocuparia posição importante nas relações culturais entre o país e a França.

Em 1836, portanto 14 anos após a Independência e 12 após o escrito de Denis, a proposta é referendada pelos letrados brasileiros. Domingos José Gonçalves de Magalhaens, estudante brasileiro, vivendo e frequentando círculos eruditos em Paris, publica um manifesto no qual assinala a relação entre uma literatura nacional e as temáticas da terra, «Discurso sobre a história da literatura brasileira». O manifesto aparece em Nitheroy, revista brasiliense - sciencias letras e artes (Magalhães, 1836), editada e impressa na França e sendo identificado imediatamente como 
referência significante do reconhecimento do ideário do romantismo enquanto constituinte de uma literatura verdadeiramente original e coerente com o novo país.

Os literatos responderam ao discurso de maneira positiva. A produção foi intensa, contribuindo para que o campo literário se autonomizasse e se tornasse mais complexo dali por diante, sem cessar.

Antes de prosseguir, é importante frisar que todo esse movimento não se restringiu ao campo literário. Fez parte de um contexto mais amplo. A ideia de identidade própria e de nacionalidade distinta de Portugal, antiga metrópole, foi um projeto de Estado. Em 1845, por exemplo, foi publicada na revista do Instituto Histórico e Geográfico Brasileiro (IGHB), a dissertação «Como se deve escrever a História do Brasil» pelo naturalista alemão Karl Friedrich Philipp von Martius ${ }^{1}$.

O IHGB era a principal instituição erudita do império. Em seus quadros militava a elite intelectual e política do país. Era apoiado pela Coroa, com o próprio Pedro II vindo a frequentar suas reuniões, como colaborador direto. Ali eram definidos ideias e pensamentos norteadores da nação. A dissertação de von Martius foi justamente isso: definiu um padrão para a constituição da identidade nacional, com todas suas contradições. Aspecto central abordado no texto foi o entendimento da miscigenação como fator positivo, que distinguiria o país dos demais, em especial dos países europeus. Transcrevo trechos em sequência:

[...] tendo para a formação do homem convergido de um modo particular três raças, a saber: a de cor cobre ou americana, a branca ou a caucasiana, e enfim a preta ou etiópica [...] Portanto, vendo nós, um povo nascer e se desenvolver da reunião e contato de tão diferentes raças humanas, podemos avançar que a sua história se deverá desenvolver segundo uma lei particular das forças diagonais [...]. (Martius, 1845)

E lança mão de argumentos formidáveis -um laico e outro teocêntrico-: «Quem poderá negar que a nação inglesa deve sua energia, sua firmeza e perseverança a essa mescla dos povos céltico, dinamarquês, romano, anglo-saxão e normando! [...] Jamais nos será permitido duvidar que a vontade da providência predestinou ao Brasil esta mescla [...]» (Martius, 1845).

Em plena vigência do regime escravocrata, que somente teria fim 43 anos depois, o texto sugere uma modulação mitigada daquela situação degradante:

E até me inclino a supor que as relações particulares, pelas quais o brasileiro permite ao negro influir no desenvolvimento da nacionalidade brasileira, designa por si o destino do país em preferência de outros estados do novo mundo, onde aquelas duas raças inferiores são excluídas no movimento geral [...]. (Martius, 1845)

Ao índio, usurpado de seus territórios, escravizado e marginalizado, é proposto um mito de origem que o identificaria como representante de antigas e poderosas civilizações, cuja verdadeira contribuição para a nova nação ainda estaria indeterminada. Indeterminação esta que von Martius atribui como de responsabilidade dos historiadores: «[...] estende-se o passado da raça americana para uma época encoberta de escuridão; e esclarecê-la será tarefa tão espinhosa quão cheia de

\footnotetext{
${ }^{1} \mathrm{O}$ naturalista viera para o Brasil com a comitiva da princesa Maria Leopoldina de Bragança, primeira imperatrizconsorte do Brasil. Ele viajou pelo norte-nordeste do país. Por ocasião da publicação do discurso, já retornara à Europa, vivendo em Munique.
} 
interesse. A vereda que o historiador deve trilhar neste campo não pode ser outra senão esta [...]» (Martius, 1845).

A dissertação é toda desenvolvida nesse tom, oferecendo soluções elevadas para o enfrentamento de uma realidade violenta, perversa e vil. Ao final, escreve:

[...] e possa seu autor, nas muitas conjecturas favoráveis, que o Brasil oferece, achar um feliz estímulo, para que imprima a sua obra todo o seu amor, todo o zelo patriótico, e aquele fogo poético próprio da juventude, ao mesmo passo que desenvolva a aplicação e profundidade de juízo e firmeza de caráter, pertencentes à idade madura e varonil. (Martius, 1845)

A superação das contradições nas relações entre dominantes e índios por meio da apropriação de sua imagem de modo positivo não é uma criação da nova nacionalidade. Desde o século XVI, ela é utilizada como representação do Novo Mundo, algumas vezes como evidência da barbárie, outras da proximidade do homem habitante do paraíso, assunto que discuti detalhadamente em outra oportunidade (Corrêa, 2006a).

No Brasil, a atitude positiva, no que se refere às representações pictóricas em relação ao índio, não esperou a tese de von Martius. Na Academia dos Renascidos, no século XVIII, ela já está presente quando a catalogação de biografias dos ilustres da terra coloca chefes indígenas ao lado de magistrados, governadores, senhores de terras e guerreiros. Um exemplo desse uso pelo Estado brasileiro é a gravura em que a figura de uma índia aparece como alegoria da terra liberta das garras da antiga metrópole -obra de 1824, durante o primeiro reinado-.

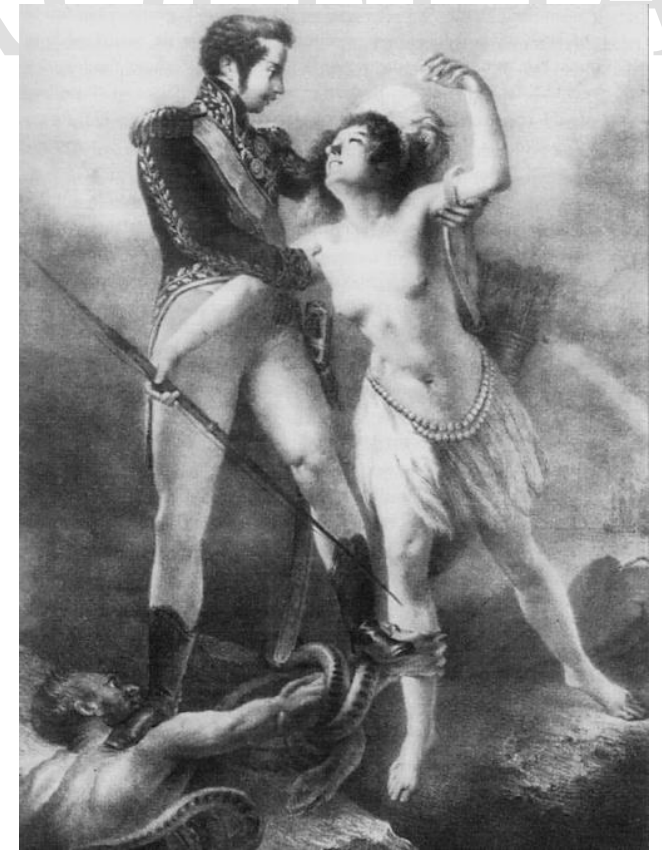

Alegoria ao Juramento da Constituição (1824)

No campo literário, a presença do índio como herói da terra já está presente no nativismo e em protagonismo ativo em obras como O Uraguai, de Basílio da Gama, publicado em Lisboa, em 1769. 
No caso, entretanto, um herói bem menos civilizado que aqueles de modelagem romântica, que lhes seriam posteriores, como é possível depreender com os trabalhos de Ivan Teixeira (1996).

No segundo reinado (1831/1840-1889)2 , os princípios propostos por Denis, Magalhaens e Martius vão adquirindo cunho de projeto determinante e determinado. Uma ideologia que é incorporada pelos agentes do campo literário, um habitus que se instala (Bourdieu, 1983). Os embates do índio com o europeu são denunciados, assim como a luta do negro pela liberdade. O índio é elevado à categoria de herói mítico da nacionalidade. O indianismo literário se torna uma vertente específica da produção romântica, no romance e na poesia. Alguns antigos historiadores de literatura, discursos constituintes do cânone, relacionam diretamente a opção pela figura do índio como a estratégia mais bem sucedida para a superação dos «exclusivos moldes portugueses» (Romero, 1953: 997).

Costumes e tradições controversos como a guerra, as relações amorosas e o canibalismo são mitificados e tratados de modo elevado. A principal poesia da temática indianista, assinada por Antônio Gonçalves Dias (1823-1863), produz mulheres sublimes, mesmo quando eróticas e sensuais. Seus discursos produzem também combatentes de alta estirpe cavalheiresca, mesmo quando imersos em costumes bárbaros.

A índia espera por seu amante, cheia de desejos. Mas seu erotismo é compatível com amores elevados, ela se identifica como mulher de um único homem: «Meus olhos outros olhos nunca viram/ Não sentiram meus lábios outros lábios,/ Nem outras mãos, Jatir, que não as tuas/ A arazoia ${ }^{3}$ na cinta me apertaram» (Dias, 1851).

As dimensões do índio são colocadas no mesmo nível que a grandeza da terra: «Aqui na floresta/ Dos ventos batida,/ Façanhas de bravos/ Não geram escravos,/ Que estimem a vida/ Sem guerra e lidar./ -Ouvi-me, Guerreiros./ -Ouvi meu cantar» (Dias, 1847). Ao final da estrofe seguinte, um questionamento, que permanecerá como distinção de si, enquanto sujeito: «Quem há como eu sou». A interrogação que o índio faz ao leitor-ouvinte não é uma dúvida, é um desafio, uma afirmação das qualidades de guerreiro e caçador -herói do novo mundo--

Em «I-Juca-Pirama», que significa «aquele que deve morrer», o ritual bárbaro de assassinato e canibalismo dos prisioneiros, que tanto horrorizou o europeu civilizado, é elevado aos níveis do combate mítico de afirmação do herói.

Entanto as mulheres com leda trigança,/ Afeitas ao rito da bárbara usança,/ O índio já querem cativo acabar: [...]/ É teu filho imbele e fraco!/ Aviltaria o triunfo/ Da mais guerreira das tribos/ Derramar seu ignóbil sangue:/ Ele chorou de cobarde;/ Nós outros, fortes Timbiras,/ Só de heróis fazemos pasto. (Dias, 1851a)

Em plena vigência da consagração do discurso literário e do índio apresentado nele como constituintes do próprio campo e da nacionalidade -experimento dizer, com Maingueneau, discursos

\footnotetext{
${ }^{2} \mathrm{O}$ período entre a barra corresponde ao da Regência, por motivo da menoridade do futuro imperador, coroado, em definitivo em 1840 .

${ }^{3}$ Um tipo de calção emplumado usado em cerimônias.
} 
constituintes, se nossa hipótese a propósito da significância da imagética do índio e do lugar da literatura para o estado brasileiro do século XIX for plausível (Maingueneau, 2006)-, surgiria uma obra que radicalizaria a crítica ao ideário hegemônico. Não através de uma crítica feita nos moldes tradicionais, condizentes com os rituais de civilidade, mas por meio de um poema debochado, escrito em linguagem baixa e escatológica. O elixir do pajé, aparecido em torno de 1875, era um poema escrito em linguagem fortemente pornográfica, sendo, portanto, da ordem do impossível de ser nomeado e enfrentado às claras: o poema circulava clandestinamente, em folhetos, segundo informam seus biógrafos. Estava, desta forma, destinado a não ser reconhecido -destinado a uma condição de invisibilidade-. Sua autoria estava sinalizada por um B. G., remetendo ao nome do juiz e autor bastante conhecido, Bernardo Joaquim da Silva Guimarães (1825-1884). Vinha, entretanto com uma epígrafe, Lasciva est nobis pagina, vita proba, retirada de Marcial (38/40-102), «Epigrammaton libri XII», liber I, epigramma IV, v.8., indiciando erudição e intimidade com os clássicos.

Poemas pornográficos, no alcance que definimos no início, fazem parte da tradição literária. Na perspectiva da literatura portuguesa, Natália Correia rompeu as barreiras da censura da ditadura salazarista e colocou em cheque as idealizações sublimes do cânone, ao publicar A poesia portuguesa erótica e satírica (dos cancioneiros medievais à atualidade), incluindo obras de autores consagrados como Camões e Jorge de Senna (Correia, 2008) ${ }^{4}$. Não é desprovido de senso sugerir, então, que aquele que se assinava B. G. sabia o que fazia.

O poema de bernardino era uma provocação absoluta a toda aquela cena discursiva constituinte do herói soberano da floresta maravilhosa, jamais escravizado. Remeto a uma leitura sintética dos trechos destacados anteriormente: na floresta, em que vivem os homens de coragem, guerreiros que nunca se tornarão escravos, qualquer que seja o resultado das guerras que travam, pois, se caírem prisioneiros, eles serão sacrificados e sua carne será comida como prova de sua coragem, posto que somente os heróis recebem esta honra! Toda a cena constituída subordinada a um ritual das antigas tradições da terra e daqueles povos, com inquestionáveis qualidades de nobreza e elevação.

A cenografia em que o índio de Bernardo Guimarães se dá a conhecer é outra. O poema começa com um lamento dissonante de uma criatura da floresta: «Que tens caralho, que pesar te oprime,/ Que assim te vejo murcho e cabisbaixo,/ Sumido entre esta imensa pentelheira,/ Mole, caindo pela perna abaixo?» (Guimarães, 1875).

Pergunta construída com palavreado baixo, de calão. Pergunta que retira imediatamente a aura do índio. As questões elevadas -honra, heroísmo, tradição- do índio canônico não aparecem aqui. O poema posiciona o personagem na principal instância do desamparo do macho -a perda da virilidade- $-^{5}$, questão eminentemente mundana. Prosseguindo no mesmo diapasão, a solução para o problema será igualmente mundana, resolvida com a simples ingestão de um elixir: «Eis um santo

\footnotetext{
${ }^{4}$ Já tive oportunidade de discutir isso em «O portal do paraíso e a floresta enfeitiçada: um estudo sobre a orgia dos duendes, de Bernardo Guimarães» (Corrêa, 2006b). E mais longamente, em minha tese, disponível em http://www.ciencialit.letras.ufrj.br/trabalhos/2006/irineueduardo_floresta.pdf.

${ }^{5}$ Questão discutida por Freud (1905).
} 
elixir miraculoso,/ Que vem de longes terras,/ Transpondo montes, serras,/ E a mim chegou por modo misterioso» (Guimarães, 1875).

As expressões elixir miraculoso, longes terras, transpondo montes e serras possíveis referentes ao índio herói do cânone, que poderiam ser empregadas e aplicadas para dizer líquido venerável e situações a serem vencidas em façanhas memoráveis, serve a intenções carnais. Realizações que colocam em evidencia uma sexualidade desprovida de qualquer rastro de sublimação-sublimidade.

«Vinde, ó putas e donzelas,/ Vinde abrir as vossas pernas/ Ao meu tremendo marzapo,/ Que a todas, feias ou belas,/ Com caralhadas eternas/ Porei as cricas em trapo.../ Graças ao santo elixir/ Que herdei do pajé bandalho,/ Vai hoje ficar em pé/ O meu cansado caralho!». (Guimarães, 1875)

Linguagem escatológica, pornográfica, sem nenhum traço de elevação para as intenções masculinas. Muito menos para o que é projetado para o feminino, que aparece apenas como objeto do desejo de um macho priápico. Nenhuma metáfora suavizante. Nenhum afeto, nem no discurso da fala do personagem, muito menos no discurso da fala do narrador. Apenas uma euforia, relacionada à solução encontrada para a situação de desamparo radical: uma expressão de uma renovada competência sexual hipertrofiada, conforme analisa Dominique Maingueneau (2010).

O Elixir do pajé é composto em duzentos e oito versos. É uma das obras mais conhecidas de seu autor, entretanto, sempre foi divulgada clandestinamente. As notícias que existem sobre a edição princeps dão conta de circular em folhetos, impressos em gráficas semiclandestinas. A primeira biografia e antologia que é publicada sobre ele -apenas um ano após sua morte- dedica um capítulo a seus poemas irônicos e fesceninos, porém quando reproduz o poema, substitui todos os calões por reticências (Coelho, 1885). Ou seja, o próprio biógrafo censura o discurso do biografado, como se quisesse mantê-lo invisível.

A partir dos anos 1970/1980 do século XX, a crítica acadêmica vem intermediando a existência do poema. Haroldo de Campos que chama a atenção para a capacidade da poesia eróticoescatológica em romper com a sincronia da cena canônica do romantismo, problematizando o que esteve presente no imaginário daquele momento -nesse quadro destaca justamente a obra bernardina (Campos, 1969)-. Luiz Costa Lima amplia o alcance da «intenção» do poema, que seria mais que uma paródia ao indianismo, pretendendo alcançar ao próprio modelo camoniano de epopeia -modelo em voga no indianismo, como visto anteriormente (Lima, 1991)-. Flora Süssekind é a primeira a denunciar a lógica da censura que impediu que o trabalho do poeta tivesse a existência reconhecida «em meio aos indianismos, arroubos de eloquência e subjetividades lacrimejantes do romantismo brasileiro» (Süssekind, 1993). Na perspectiva daquela idealização não haveria lugar para um velho debochado e sua sexualidade, expostos ambos com todas as letras.

Assumir a hipótese da lógica da censura específica para o poema do elixir seria, talvez, negar o difícil lugar de toda e qualquer obra pornográfica no campo literário. Um lugar dentro do campo não encontrei crítico que lhe negue este pertencimento, embora todos o problematizem-. A condição de invisibilidade dos discursos com estas características tem sido observada nas histórias da 
literatura, nas antologias, nas biografias, bem como na crítica e nas bibliotecas. Nestas últimas, como observei em outra oportunidade (Corrêa, 2007).

Considerando, entretanto anota Flora Süssekind, no texto citado linhas acima, estaríamos diante de um fato singular: Bernardo Guimarães foi romancista de renome, grandes leitores, Machado de Assis e Manuel Bandeira, entre eles, reconhecem sua produção poética como de alta qualidade. Seu nome, contudo, é significante de uma obra de segunda linha, segundo histórias e antologias de literatura. Aparece, então, uma questão teorizada pela análise do discurso, de concepção francesa: a interdiscursividade (Maingueneau, 2000) em que um discurso emerge teria força suficiente para determinar quase de modo absoluto o lugar de uma obra. Os discursos sobre uma obra seriam forças determinantes da paratopia (Maingueneau, 2001 e 2006) de um autor, independente da época e do gênero. Seria possível afirmar, então, que a rede interdiscursiva teria mais força que o próprio discurso, para estabelecer seus significados?

Com está questão lançado, encerro!

\section{Referencias bibliográficas}

Bourdieu, P. (1983): Sociologia, R. Ortiz, org. São Paulo, Ática.

CAmpos, H. de (1969): «Poesia sincrônica», en A arte no horizonte do provável. São Paulo, Perspectiva, 1977, pp. 205-212.

Coelho, J. M. V. P. (1885): Poesias e romances do dr. Bernardo Guimarães. Rio de Janeiro, Typ. Universal de Laemmert.

CorrêA, I. E. J. (2006a): «O elixir do pajé de Bernardo Guimarães», Ciências e Letras, en http://www1.fapa.com.br/cienciaseletras/pdf/revista39/art7.pdf?origin=publication_detail (última consulta, 29-01-2015).

(2006b): «O portal do paraíso e a floresta enfeitiçada: um estudo sobre a orgia dos duendes, de Bernardo Guimarães», Terceira Margem, 15, pp. 205-223.

(2007): «Notas sobre uma coleção invisível: a censura e as obras clássicas no acervo da Biblioteca Nacional», Anais da Biblioteca Nacional, 122, pp. 7-48.

Correia, N. (2008): Antologia de poesia portuguesa erótica e satírica. Lisboa, Antígona/Frenesi.

DENIS, F. J. (1824): Scènes de la nature sous les Tropiques et de leur influence sur la poésie, suivies de Camoens et Jozé Indio, par Ferdinand Denis. Paris, L. Janet.

Dias, G. (1847): «O canto do guerreiro», en A. Bueno, org., Primeiros cantos, Gonçalves Dias: poesia e prosa completas. Rio de Janeiro, Nova Aguliar, 1998, pp. 106-108.

_ (1851a): «I-Juca-Pirama», en A. Bueno, org., Últimos cantos, Gonçalves Dias: poesia e prosa completas. Rio de Janeiro, Nova Aguliar, 1998, pp. 379-393.

(1851b): «Leito de folhas verdes», en A. Bueno, org., Últimos cantos, Gonçalves Dias: poesia e prosa completas. Rio de Janeiro, Nova Aguliar, 1998, pp. 377-378.

Foucault, M. (1996): A ordem do discurso. São Paulo, Edições Loyola.

FREUD, Sigmund (1905): Três ensaios sobre a sexualidade. 
LIMA, L. C. (1991): «Bernardo Guimarães e o cânone», en Pensando nos trópicos. Rio de Janeiro, Vozes, pp. 241-252.

Magalhaens, G. de (1836): «Discurso sobre a história da literatura brasileira», Nitheroy: revista brasiliense, sciencias, letras e artes, pp. 122-159.

Maingueneau, D. (2000): Termos chave da análise do discurso. Trad. de Márcio Venício Barbosa e Ma. Emília Amarante T. Lima, Belo Horizonte, Editora da UFMG.

- (2001): O contexto de obra literária. Trad. de M. Appenzeller e E. Brandão. São Paulo, Martins Fontes, $2^{\mathrm{a}}$ ed.

_ (2006): Discurso literário. Trad. de A. Sobral. São Paulo, Contexto. (2010): Discurso Pornográfico. São Paulo, Parábola Editorial.

Martius, K. F. Ph. (1845): «Como se deve escrever a História do Brasil», Revista do IHGB, 6/24, pp. 389-411.

Romero, S. (1953): História da literatura brasileira. Rio de Janeiro, José Olympio Editora, tomo terceiro, $5^{\text {a }}$ ed., p. 997.

SAlve! Querido Brasileiro Dia (1924): 25 de março. Alegoria ao Juramento da Constituição, «Gianni fecit». Lith. De Lasteyrie. S.d. Litogravura. 84 X $57 \mathrm{~cm}$. Coleção Fundação Biblioteca Nacional.

SusseKIND, F. (1993): «Bernardo Guimarães; romantismo com pé-de-cabra», en Papéis colados. Rio de Janeiro, Editora UFRJ, pp. 139-150.

TeIXeIRA, I. (1996): Obras poéticas de Basílio da Gama. São Paulo, Edusp. 